\title{
CARACTERÍSTICAS VOCAIS DO CANTO JAPONÊS NOS GÊNEROS ENKA E MUDO ENKA
}

\author{
Vocal characteristics of Enka and Mudo Enka \\ genre of Japanese singing
}

\author{
Cintia Megumi Nishimura (1), Zuleica Camargo (2), Gislaine Ferro Cordeiro ${ }^{(3)}$, \\ Sílvia Maria Rebelo Pinho ${ }^{(4)}$
}

\begin{abstract}
RESUMO
Objetivo: comparar do ponto de vista perceptivo-auditivo as características vocais dos gêneros do canto japonês enka e mudo enka. Métodos: foram selecionadas dez gravações em CD comercialmente disponíveis de cinco cantores japoneses profissionais que caracterizam o gênero enka e cinco do estilo mudo enka. Foram elaborados um protocolo de avaliação de voz com características vocais encontradas nos dois estilos da música japonesa. A avaliação foi realizada por três fonoaudiólogas especialistas na área de voz pelo Conselho Federal de Fonoaudiologia, determinando as características vocais mais marcantes em cada gênero a partir da classificação baseada na literatura. Resultados: no estilo enka, o kobushi, o vibrato e crescendos e decrescendos esteve presente em $100 \%$ das amostras vocais. Foi encontrado $80 \%$ de metal, $90 \%$ de nasalidade e alternância de registro e $70 \%$ de soprosidade. No estilo mudo enka, os crescendos e decrescendos esteve presente em $100 \%$ das amostras vocais. Foi encontrado $70 \%$ de soprosidade, $90 \%$ de vibrato, $50 \%$ de alternância de registro, $40 \%$ de metal e $20 \%$ de nasalidade e kobushi. Conclusão: Comparando-se os dois gêneros musicais, enka e mudo enka, identificou-se a presença marcante do Kobushi no gênero enka além do maior predomínio de vibrato, metal, nasalidade, alternância de registros e crescendos e decrescendos. A soprosidade foi encontrada em igual proporção em relação aos dois estilos musicais. A identificação das características vocais é útil ao fonoaudiólogo bem como ao professor de canto no atendimento de cantores durante o aprendizado do canto japonês e ou no aperfeiçoamento.
\end{abstract}

DESCRITORES: Voz; Avaliação; Percepção Auditiva

\section{INTRODUÇÃO}

A música sempre fez parte da tradição e da vida dos japoneses, como forma de extravasar alegria e também de transmitir a cultura dos antepassados.

No Japão, a música e a arte de cantar são muito valorizadas e apreciadas. O canto faz parte das disciplinas escolares, e esta prática é aplicada às crianças ainda bem pequenas.

(1) Fonoaudióloga da Clínica Medicenter; Especialização em Voz.

(2) Fonoaudióloga, Professora Assistente-Doutora do Departamento de Lingüística da Faculdade de Comunicação e Filosofia da Pontifícia Universidade Católica de São Paulo; Doutora em Lingüística Aplicada e Estudos da Linguagem pela Pontifícia Universidade Católica de São Paulo.

(3) Fonoaudióloga, Professora Assistente do Instituto da Voz Comunicação e Voz Profissional, Especialização em Voz.

(4) Fonoaudióloga, Diretora do INVOZ-Instituto da Voz; Doutora em Distúrbios da Comunicação Humana pela Universidade Federal de São Paulo.
Igualmente no Brasil, muitas apresentações e concursos da canção japonesa são realizados. Nestes concursos, os cantores amadores submetem-se à avaliação da comissão julgadora constituída de professores de canto japonês e músicos. As avaliações são realizadas individualmente durante as apresentações, e o cantor acompanha o karaokê ou conjunto musical. A cada ano, cresce o número destas apresentações e concursos entre pessoas até mesmo de outras descendências.

Dessa forma, nos consultórios fonoaudiólogicos cresce a procura de cantores da música japonesa, interessados em tratar patologias vocais e até mesmo para aprimoramento de suas técnicas. As alterações vocais surgem provavelmente, por não apresentar saúde vocal ${ }^{1-3}$ e por falta de conhecimento da técnica vocal ${ }^{4}$, e das características musicais de cada gênero da música japonesa.

A história tradicional da música japonesa pode ser dividida em cinco períodos, correspondendo aos períodos principais de desenvolvimento social, políti- 
co e econômico: Ancião (século VI), quando o período era da música nativa; ancião recente (século VII), período da música internacional; Idade Média (entre século XI e XVI), período da música nacional; Idade Média recente (século XVII até 1868), música nacional; Tempos Modernos (1868 em diante) período em que a música se tornou mundial ${ }^{5}$.

A música tradicional japonesa é caracterizada por vários gêneros. Por mais que o tempo passe, quando um gênero musical se estabelece, ele é transmitido às gerações futuras, produzindo-se cada um deles sem misturarse aos outros. Faz parte da cultura japonesa a tendência a manter a tradição. Desta forma, temos o gênero Gagaku e Biwa, da corte imperial, o nogaku dos samurais, o shamisen do povo, o shomyo dos templos e a canção folclórica dos camponeses que coexistem até hoje ${ }^{6}$.

Todavia, a cultura milenar japonesa introduzida por seus imigrantes há cem anos no Brasil mantém até hoje suas tradições. Ocorre no arranjo floral ikebana; na cerimônia do chá cha-no-yu; na pintura; na caligrafia artística; na arte de jardinagem, na arquitetura; na cozinha ${ }^{7}$; na dança e na música.

Os gêneros musicais da música japonesa são Enka, New Enka e Mudo Enka ${ }^{6}$. Os demais gêneros são aqueles conhecidos mundialmente, como a música pop, dance e rock ${ }^{6}$.

Enka é o gênero musical tradicional do Japão ${ }^{6}$. Foi descrito como a alma do Japão, corresponde a música popular japonesa ${ }^{8}$. É definida como música declamada, de ressentimentos das pessoas convertidas em música ${ }^{6}$. Enka vem da palavra enzetsu, que significa discurso público; e ka, significa canção ${ }^{8}$. Surgiu na segunda década da Era Meiji (1868-1912) ${ }^{9}$, quando o Japão abriu as portas ao mundo exterior, aproximadamente após 250 anos de isolamento. Houve então, rápida transformação em uma sociedade industrial moderna. Como parte das reformas da Era Meiji, foram permitidos os partidos políticos com proibição de discursos em público ${ }^{10}$.

O gênero enka, teve origem a partir de um discurso político que foi transformado em canção, com o objetivo de chamar atenção do povo durante um comíssio e difundir o pensamento de liberdade e direitos populares. Posteriormente, foi afastado do meio político e casos de amores proibidos, trágicos e de suicídios de amantes passaram a ser cantados pelas ruas ao som do shamissen, koto, acordeão, violino, violão. Desta forma, as letras das músicas, passaram a ser comercializadas. Naquela época, não se vendia a composição da música, e sim, a letra ${ }^{10}$.

Para cantar músicas do gênero enka, as mulheres geralmente vestem o kimono, roupa tradicional japonesa feminina, ou às vezes, vestido de noite. Os homens, usam ternos ou ohakama, roupa tradicional japonesa masculina ${ }^{11}$.

O gênero New Enka é originária do estilo Enka. Refere-se como uma música moderna, de ritmo alegre. É a mistura entre o estilo romântico ao declamado ${ }^{8}$.

Mudo enka é o gênero musical romântico, no qual o ritmo é lento e a letra da música geralmente referese a sentimentos amorosos ${ }^{6}$.

A respiração diafragmática, utilizada durante 0 sono ${ }^{4}$ e a contração abdominal é referida com de grande importância no canto japonês. Segundo cantores nativos este padrão respiratório influencia na tonalidade da voz e no vibrato, facilitando a expressão vocal e interpretação da música ${ }^{12}$.

Dentre as características ornamentais do canto japonês, o "Kobushi" é referido como sendo um vibrato lento ${ }^{9}$, um acessório da voz ${ }^{13}$, um ornamento ${ }^{12,14}$ muito encontrado na música japonesa. Corresponde a criatividade do cantor fora da partitura ${ }^{14}$. É uma das técnicas mais importantes para cantar a música japonesa ${ }^{14}$.

Antigamente os compositores não colocavam nas partituras ornamentos individuais para os cantores, mas atualmente, na composição da música, o "Kobushi" é marcado na partitura ${ }^{14}$. Outros autores consideram o "Kobushi" como uma flutuação da voz,

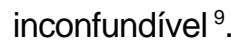

O vibrato é modulação de freqüência ${ }^{13}$, variação rítmica repetida da freqüência fundamental ${ }^{15}$. É mais utilizado na música japonesa clássica ${ }^{12}$.

A interpretação da letra da música, a transmissão de sentimentos, muito valorizado no canto japonês, é resultante da abertura da boca adequada ao pronunciar cada vogal e em transmitir o sentimento a cada palavra cantada. É necessário interpretar bem para ser apreciado ${ }^{12}$.

O falsete expressa a fragilidade feminina, tristeza, fraqueza. Algumas cantoras japonesas profissionais utilizam o falsete ${ }^{12}$.

Alguns autores referem que a música japonesa caracteriza-se pelos sons fortes guturais e retidos. Para os europeus, a voz cantada nas músicas japonesas soa muito comprimida e dura ${ }^{16}$.

Existem vários estudos sobre aspetos perceptivos e acústicos, além de estudos de fisiologia relativos aos cantos: lírico ${ }^{17,18}$, coral ${ }^{1,19-22}$ popular ${ }^{15,23-25}$ samba $^{26}$, gospel ${ }^{27}$,pagode ${ }^{28}$, entretanto, poucos estudos foram realizados investigando 0 canto japonês nesta área.

Portanto, é importante conhecer mais a respeito da cultura japonesa, assim como as técnicas e as características vocais de cada gênero da música japonesa, para que haja melhor condução de cada caso no atendimento fonoaudiológico desses indivíduos, uma vez que há escassez na literatura sobre o canto japonês.

Este estudo tem como objetivo, identificar as características vocais da música japonesa por meio de análise perceptivo-auditiva de vozes de cantores profissionais japoneses nos gêneros enka e mudo enka. 


\section{MÉTODOS}

Foram utilizados como critério de inclusão, amostras vocais de cantores japoneses profissionais adultos, consagrados pelo público japonês, por meio de amostras selecionadas de CD's comercializados no Japão nos gêneros musicais enka e mudo enka. Foram excluídos cantores infantis (abaixo de 18 anos) e idosos (acima de 60 anos), cantores de outros estilos musicais e cantores não nativos no Japão.

Foram selecionadas por dois indivíduos familiarizados com a música japonesa dez gravações em CD comercialmente disponíveis, sendo cinco amostras vocais de cinco cantores japoneses profissionais reconhecidos, utilizando-se do gênero enka e cinco amostras de cantores japoneses profissionais reconhecidos utilizando-se do gênero mudo enka. Ambos os indivíduos eram familiarizados e treinados no gênero enka e mudo enka, sendo um deles, do gênero masculino, japonês nato e professor de canto japonês e o outro, do gênero feminino, descendente de japoneses, consagrada campeã Brasileira da Canção Japonesa, com prêmios no exterior, inclusive no Japão.

As amostras selecionadas foram gravadas duas vezes cada, de forma aleatória quanto aos gêneros musicais, totalizando 20 amostras para a análise.

Dentre as músicas selecionadas, os examinadores definiram cada uma das características vocais encontradas de forma marcante em cada gênero e elaboraram um protocolo de avaliação no qual constam os itens que caracterizam os ornamentos vocais utilizados para os dois estilos de canto, com suas respectivas definições: enka ${ }^{6,8-10}$ e mudo enka ${ }^{6}$. Todos os ornamentos definidos foram demonstrados por um dos indivíduos treinados na técnica.

$\mathrm{Na}$ segunda etapa de avaliação, três fonoaudiólogas experientes em avaliação perceptivoauditiva da voz, as quais nunca tiveram contato com a música japonesa, realizaram a avaliação das gravações de acordo com as definições previamente estabelecidas na etapa anterior, determinando as características vocais mais marcantes em cada música apresentada, preenchendo o roteiro de avaliação perceptivo-auditiva.

As vinte amostras de músicas japonesas foram apresentadas aleatoriamente às três fonoaudiólogas que realizaram a análise perceptivo-auditiva. Cada amostra de voz foi ouvida três vezes. As examinadoras foram solicitadas a identificar na música, as seguintes características: kobushi, vibrato, soprosidade, metal, nasalidade, alternância de registro, utilização de crescendos e decrescendos, conforme os graus de manifestação (0) para ausente, (1) para leve, (2) para moderado, (3) para intenso.

No início da análise, a pesquisadora treinada no canto japonês, definiu e demonstrou para as participantes da pesquisa, cada uma das características vocais existentes no roteiro de avaliação perceptivoauditiva. Sendo que, durante a análise, as fonoaudiólogas não foram avisadas de quais músicas eram do gênero enka e do mudo enka.

As amostras de voz foram reproduzidas em equipamento Superscope CD Record Systen PSD 300 gravador de CD, em uma sala silenciosa.

Em seguida iniciaram-se as análises para a identificação dos aspectos vocais mais marcantes ou mais reconhecidos em cada gênero musical.

A presente pesquisa foi avaliada e aprovada pelo Comitê de Ética em Pesquisa do Centro de Especialização em Fonoaudiologia Clínica, sob no 130/06.

Os dados foram organizados e apresentados por meio de distribuição de freqüência simples e percentual, utilizando o programa Excel 2003. Para análise estatística, os dados obtidos foram apresentados em frequências relativas e gráficos e submeteram-se ao teste Qui-quadrado, considerando-se como nível de significância 0,05.

\section{Protocolo de avaliação perceptivo - auditiva}

a) Kobushi: vibrato lento ${ }^{9}$, flutuação da voz ${ }^{11}$, ornamento ${ }^{12,14}$ existente em algumas $\mathrm{m}$ úsicas japonesas ${ }^{12}$.

Manifestação-( ) 0 -ausente ( )1-leve ( )2-moderado ( ) 3-intenso

b) Vibrato: variação rítmica repetida da frequência fundamental ${ }^{15}$.

Manifestação-( ) 0 -ausente ( )1-leve ( )2-moderado ( ) 3 -intenso

c) Soprosidade: corresponde à presença de ruido de fundo, audivel e o correlato fisiológico

mais freqüente é a presença de fenda glótica ${ }^{4}$.

Manifestação-( ) 0 -ausente ( )1-leve ( ) 2-moderado ( ) 3-intenso 
d) Metal: característica vocal causada por constrições parciais do trato vocal ${ }^{4}$, hipertonicidade de constritores laríngeos ${ }^{29}$ tornando a voz mais audivel ${ }^{4}$.

Manifestação-( ) 0 -ausente ( ) 1-leve ( ) 2-moderado ( ) 3-intenso

e) Nasalidade: desvio do fluxo oral para cavidade nasal em sons orais ${ }^{4}$.

Manifestação-( ) 0 -ausente ( )1-leve ( )2-moderado ( ) 3-intenso

f) Alternância de registro: mudança do predomínio muscular ao produzir sons da tessitura vocal ${ }^{4}$.

Manifestação-( ) 0 -ausente ( )1-leve ( ) 2-moderado ( ) 3-intenso

g) Utilização de crescendos e decrescendos: aumento e diminuição da intensidade da voz.

Manifestação-( ) 0 -ausente ( )1-leve ( )2-moderado ( ) 3 -intenso

\section{RESULTADOS}

As informações referentes à manifestação do Kobushi nas músicas japonesas nos gêneros enka e mudo enka são apresentadas na Figura 1.

Os resultados obtidos indicam que no gênero enka, o Kobushi esteve presente em $100 \%$ das amostras vocais, sendo $60 \%$ de grau intenso. No gênero mudo enka, esta característica esteve presente em apenas $20 \%$ em grau leve.

As informações referentes à manifestação do vibrato nas músicas japonesas nos gêneros enka e mudo enka são apresentadas na Figura 2.

Observou-se que no gênero enka, o vibrato esteve presente em $100 \%$, sendo observado em $60 \%$ grau moderado. No gênero mudo enka, esta característica esteve presente em $90 \%$ das amostras mas, com predomínio de $60 \%$ em grau leve.

As informações referentes à manifestação da soprosidade nas músicas japonesas nos gêneros enka e mudo enka são apresentadas na Figura 3.

Nos dois gêneros musicais foi encontrado o mesmo percentual em relação à soprosidade, ou seja, $70 \%$ em grau leve.

As informações referentes à manifestação de metal nas músicas japonesas nos gêneros enka e mudo enka são apresentadas na Figura 4.

Os resultados obtidos demonstram que no gênero enka, $80 \%$ das amostras vocais apresentaram o metal, sendo predominante o grau moderado em $40 \%$. No estilo mudo enka, esta característica foi encontrada em apenas $40 \%$ com predomínio de $30 \%$ em grau leve.

As informações referentes à manifestação da nasalidade nas músicas japonesas nos gêneros enka e mudo enka são apresentadas na Figura 5.
Outra característica estudada foi a nasalidade, encontrada em $90 \%$ no gênero enka, com predomínio de grau leve. No gênero mudo enka, apenas 20\% de grau leve foi encontrado.

As informações referentes à manifestação de alternância de registros nas músicas japonesas nos gêneros enka e mudo enka são apresentadas na Figura 6.

Os resultados obtidos indicam que no gênero enka a alternância de registros está presente em $90 \%$ das amostras vocais, sendo $70 \%$ em grau leve. E no gênero mudo enka, $50 \%$, sendo $40 \%$ também em grau leve.

As informações referentes à manifestação de crescendos e decrescendos nas músicas japonesas nos gêneros enka e mudo enka são apresentadas na Figura 7.

Com relação aos crescendos e decrescendos estão $100 \%$ presentes em ambos os gêneros musicais, porém $60 \%$ e $40 \%$ em grau moderado no gênero enka e mudo enka respectivamente.

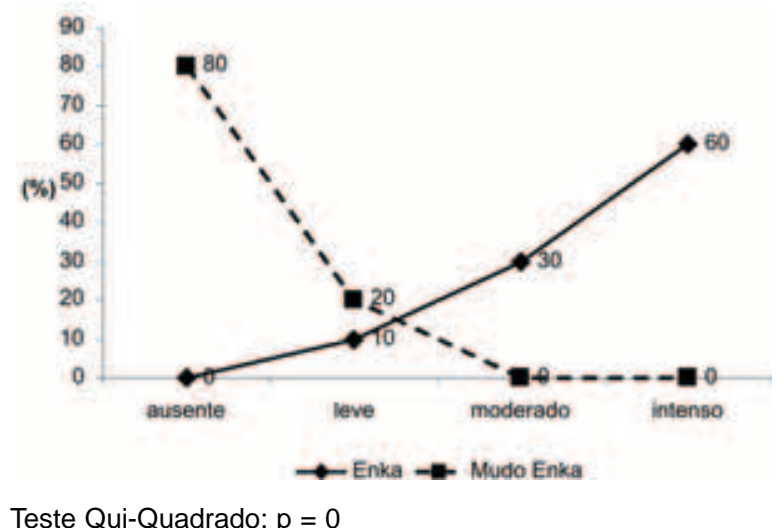

Figura 1 - Representação do Kobushi em porcentagem para manifestação em graus ausentes, leves, moderados e intenso nos estilos enka e mudo enka 


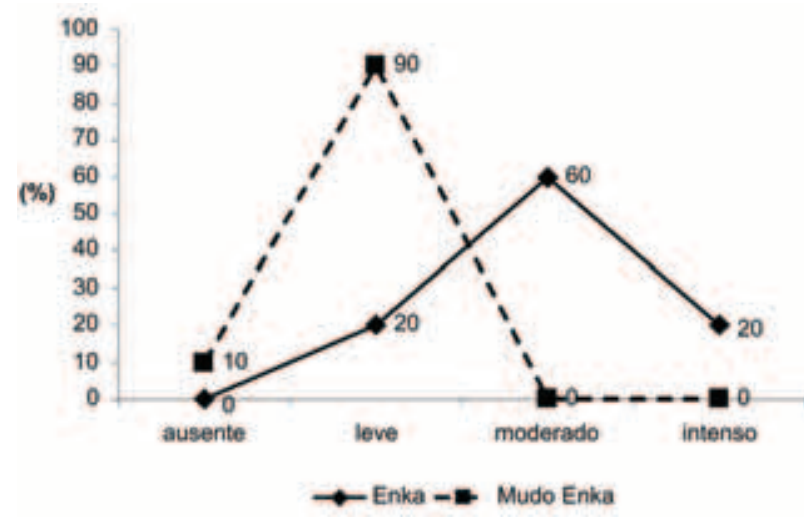

Teste Qui-Quadrado: $p=0$

Figura 2 - Representação do vibrato em porcentagem para manifestação em graus ausentes, leves, moderados e intenso nos estilos enka e mudo enka

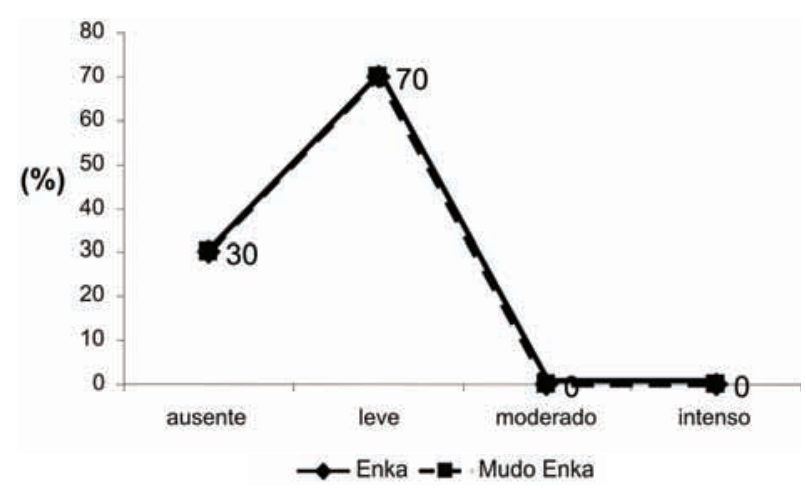

Teste Qui-Quadrado: $p=0$

Figura 3 - Representação da soprosidade em porcentagem para manifestação em graus ausentes, leves, moderados e intenso nos estilos enka e mudo enka

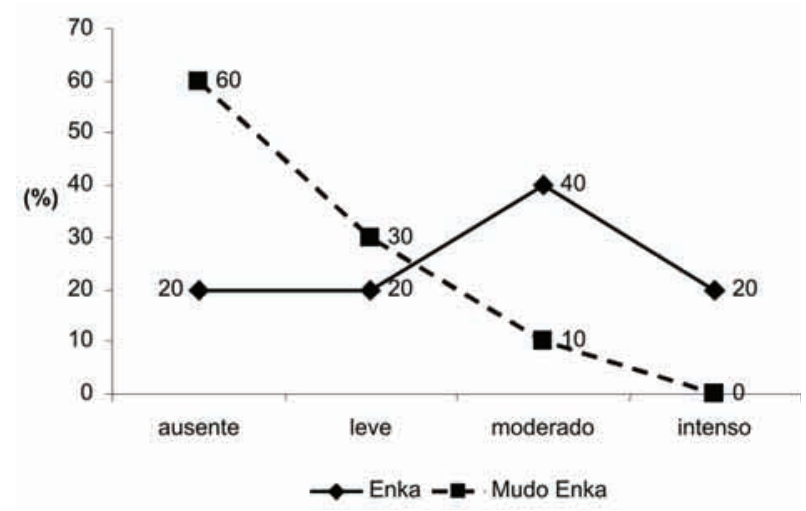

Teste Qui-Quadrado: $p=0$

Figura 4 - Representação de metal em porcentagem para manifestação em graus ausentes, leves, moderados e intenso nos estilos enka e mudo enka

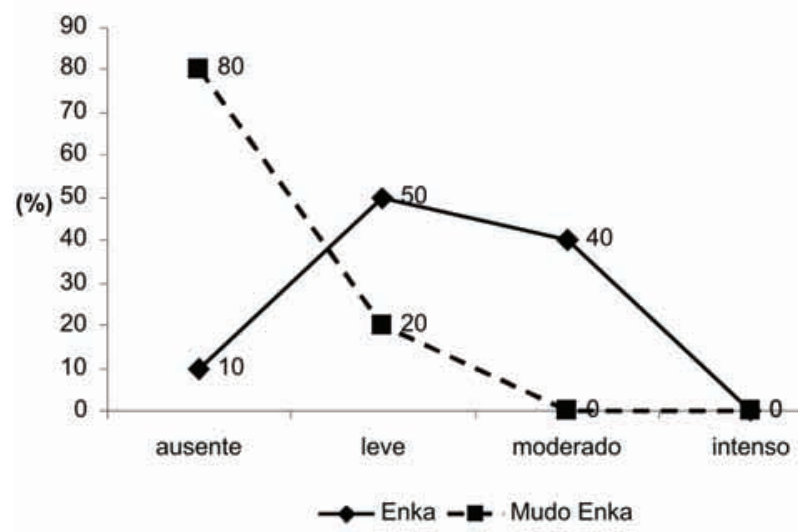

Teste Qui-Quadrado: $p=0$

Figura 5 - Representação da nasalidade em porcentagem para manifestação em graus ausentes, leves, moderados e intenso nos estilos enka e mudo enka

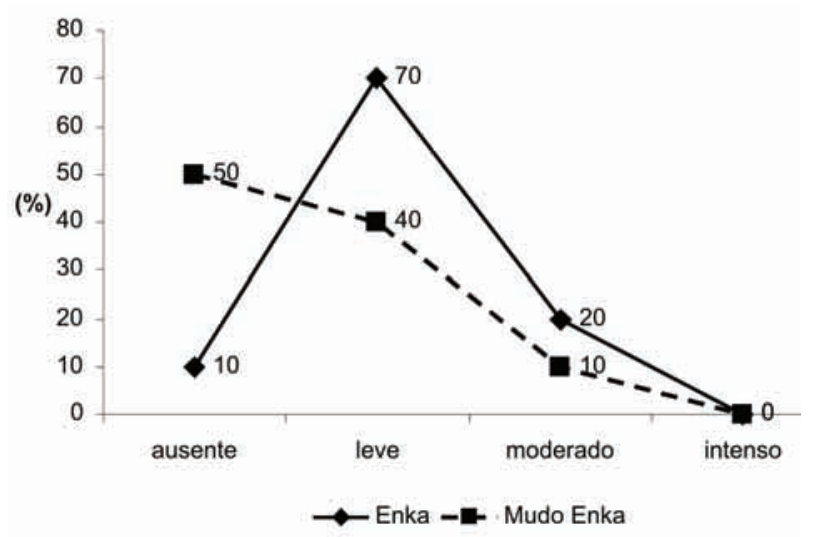

Teste Qui-Quadrado: $p=0$

Figura 6 - Representação de alternância de registro em porcentagem para manifestação em graus ausentes, leves, moderados e intenso nos estilos enka e mudo enka

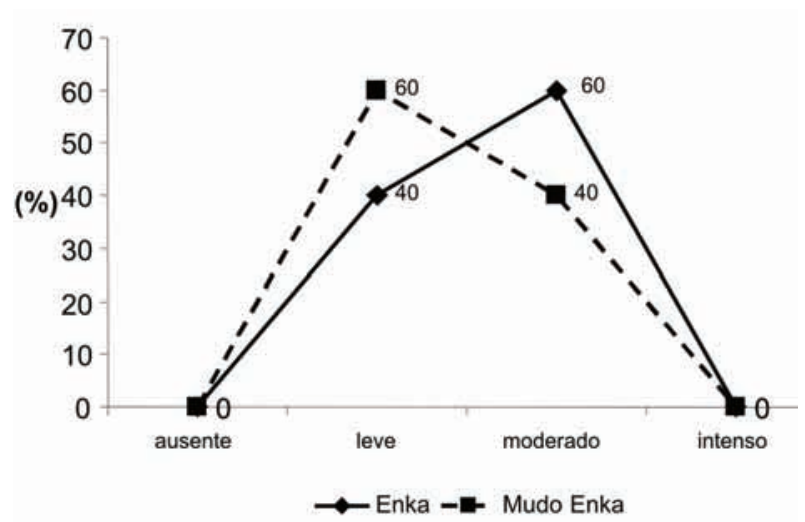

Teste Qui-Quadrado: $p=0$

Figura 7 - Representação de crescendos e decrescendos em porcentagem para manifestação em graus ausentes, leves, moderados e intenso nos estilos enka e mudo enka 


\section{DISCUSSÃO}

O presente estudo foi realizado nos gêneros enka e mudo enka por ser bastante apreciado e cantado, tanto no Japão quanto no Brasil.

Os diversos gêneros do canto japonês vêm sendo tema de discussão entre professores de canto e fonoaudiólogos no Brasil, devido à grande demanda de cantores iniciantes na modalidade, imigrantes, descendentes ou até mesmo por indivíduos de outras descendências, estimulados pelos inúmeros concursos de canto japonês realizados em nosso país.

Concursos nacionais e internacionais são realizados com freqüência. Participam em média, 750 cantores em Concursos Brasileiros da Canção Japonesa. Estes eventos são realizados como forma de confraternização, onde participam pessoas que apreciam a música.

Há aproximadamente cem anos, houve a imigração japonesa e desde então, o ato de cantar vem sendo praticado e estimulado no meio. O canto faz parte da cultura japonesa, sendo assim, mesmo que os indivíduos que praticam o canto japonês como amadores, praticam aula de canto, treinam e dedicam-se para cantar bem e utilizar corretamente as técnicas vocais.

Para melhor atender este público e ajudar a preservar sua tradição é necessário conhecer os tipos de canto existentes mantendo suas características originais.

A interpretação da letra da música é muito importante, e é o primeiro requisito da música japonesa ${ }^{12}$. Os vários ornamentos utilizados nos diversos gêneros musicais vão caracterizar sentimentos diferentes. A soprosidade observada em alguns momentos, em ambos os gêneros enka e mudo enka pode conferir um sentimento de sensualidade ou doçura à voz.

Uma das características marcantes do canto japonês no gênero enka encontrado neste trabalho foi o Kobushi ${ }^{9,11,12,14}$. Diferentemente do que foi encontrado no gênero mudo enka.

O vibrato ${ }^{13,15}$, tem a finalidade de acrescentar beleza, riqueza expressiva à voz além de conferir maior sentimento ${ }^{11}$. O vibrato constitui uma característica marcante encontrada nos dois gêneros da música japonesa, mas predominante no gênero enka.

Crescendos e decrescendos foram encontrados em ambos gêneros musicais. É um ornamento que caracteriza uma forma também de interpretar e demonstrar técnica. Para esta prática, prioriza-se o apoio respiratório.

O metal ${ }^{4,29}$, a nasalidade e a alternância de registro ${ }^{4}$ foram encontrados em ambos os gêneros musicais, porém com maior predomínio no gênero enka. Estes recursos não são encontrados com freqüência na música romântica moderna.

Supõe-se que, as características vocais encontradas na literatura do canto japonês como dura e comprimida ${ }^{16}$, foram encontradas ao analisar a voz em outro gênero, como na música folclórica japonesa, o "Minyo". Durante o processo de seleção nenhum dos dois sujeitos (professor de canto e cantora premiada) que selecionaram os dois padrões para análise: enka e mudo enka consideraram a presença destas características.

A música japonesa sofreu a influência de várias culturas e a partir de 1868 começa a se transformar até os dias atuais com a introdução do romantismo. Desta forma, o mudo enka não apresenta características marcantes originais aproximando-se mais da música ocidental romântica moderna.

O estudo dos aspectos acústicos e da dinâmica do trato vocal de ambos os gêneros de canto japonês, enka e mudo enka serão realizados em estudos futuros.

\section{CONCLUSÃO}

1) Existem diferenças entre as características vocais utilizadas nos dois gêneros musicais. Comparando-se os dois gêneros musicais, enka e mudo enka, identificou-se a presença marcante do Kobushi no gênero enka além do maior predomínio de vibrato, metal, nasalidade, alternância de registros e crescendos e decrescendos. A soprosidade foi encontrada em igual proporção em relação aos dois gêneros musicais.

2) A identificação das características vocais utilizadas nos dois gêneros musicais, enka e mudo enka, é útil tanto ao fonoaudiólogo como ao professor de canto no atendimento de cantores durante o aprendizado do canto japonês ou no aperfeiçoamento deste nos diferentes gêneros.

3) A definição das características vocais utilizadas nos gêneros enka e mudo enka, contribui para manter a tradição do canto japonês no Brasil.

\section{AGRADECIMENTO}

Prof. Ricardo R. Origassa 


\begin{abstract}
Purpose: to compare from a perceptual perspective the vocal characteristics of enka and mudo enka Japanese singing genre. Methods: ten recordings, from commercially available CDs, of five professional Japanese singers who sing the enka genre and five of the mudo enka genre were selected. We elaborated a voice evaluation protocol with vocal characteristics found in both genres of Japanese music. The evaluation was carried out by three speech pathologists, licensed by the Speech Pathology Federal Board, who determined the most outstanding vocal characteristics of each genre, from a literature-based stratification. Results: in the enka genre, the kobushi, the vibrato and crescendos and decrescendos were present in $100 \%$ of the vocal samples. We found $80 \%$ of metal, $90 \%$ of nasality and registration alternation and $70 \%$ of soprosity. In the mudo enka genre, the crescendos and decrescendos were present in $100 \%$ of the vocal samples. We found $70 \%$ of soprosity, $90 \%$ of vibrato, $50 \%$ of registration alternation, $40 \%$ of metal and $20 \%$ of nasality and kobushi. Conclusion: When comparing the two genres, enka and mudo enka, we verified the strong presence of Kobushi in the enka genre, along with a larger predominance of vibrato, metal, nasality, alternation of registrations and crescendos and decrescendos. The soprosity was found in equal rates in both genres. The identification of vocal characteristics is useful for the speech pathologist as well as singing professors when helping their clients (singers) during the learning of the Japanese singing or in its improvement.
\end{abstract}

\title{
KEYWORDS: Voice; Evaluation; Auditory Perception
}

\section{REFERÊNCIAS}

1. Pinho SMR. Manual de higiene vocal para profissionais da voz. Carapicuíba: Pró-fono; 1997.

2. Guedes BS, Kasai RCB. Bares e saúde vocal dos cantores. J Bras Fonoaudiol. 2001; 3(9):287-94.

3. Grillo MHMM, Penteado RZ. Impacto da voz na qualidade de vida de professore(a)s do ensino fundamental. Pró-Fono R Atual Cient. 2005; 17(3):311-20. 4. Pinho SMR. Fundamentos em fonoaudiologia: tratando os distúrbios da voz. 2. ed. Rio de Janeiro: Guanabara-Koogan; 2003. 25 p.

5. Shigueo K. The traditional music of Japan. Tokyo: Ongaku no tomo sha Edition; 1984. 1-30 p.

6.Makio C. Música japonesa. Aliança Cultural Brasil e Japão. São Paulo. Disponível em: URL: http:// www.acbj.com.br/alianca/palavras.php?Palavra $=36$.

7. Kiyotani M, Kisaka K. Uma epopéia moderna: 80 anos da imigração japonesa no Brasil. São Paulo: Hucitec; 1992.

8. Japan Travel Guide. Enka: Japan's soul music. Disponível em: URL:

http://www.travelotica.com/travelguide/181/japan/ enka-japans-soul-music-8708.htm.

9. Enka. Tokyo; Revista Ministério da Cultura do Japão. 1905.

10. Cahoon K. Just what is Enka, anyway? Disponível em: URL:

http://nippop.com/features/feature_id-6 .

11. "Enka" is also a? Disponível em: URL: http:// everything2.org/?node_id=726087

12. Ito Y. Master karaokê. 2. Ed. Tokyo: Karaokê Fã; 1997. p. 13-61.
13. Wada H. Enka no Utaikata, Nihon Ongaku kyouiku Senta: Tokyo, Japan; 4 p.

14. Dinville C. A técnica da voz cantada. 2. ed. Rio de Janeiro: Enelivros; 1993. 8 p.

15. Pinho SMR, Tsuji DH. Fundamentos em laringologia e voz. Rio de Janeiro: Revinter; 2006. 48 p.

16. Perelló J, Guitart E, Caballé M. Canto-dicción. Barcelona: Científico-Médica; $1982.8 \mathrm{p}$.

17. Zampieri SA, Behlau M, Osíris OC. Análise de cantores de baile em estilo de canto popular e lírico: perceptivo-auditiva, acústica e da configuração laríngea. Rev Bras Otorrinolaringol. 2002; 68(3):378-86.

18. Facincani MFO, Novaes RM, Ferretti E, Behlau M. Análise de parâmetros vocais e avaliação videolaringoscópica pré e pós-aquecimento vocal em cantores líricos. In: Behlau M. A voz do especialista. v.1. Rio de Janeiro: Revinter; 2001. p. 151-9.

19. Guarda E. El canto coral en el sur de Chile. Rev Mus Chil. 2001; 55(195):69-70.

20. Costa PJBM, Ferreira KL, Camargo ZA, Pinho SMR. Extensão vocal de cantores de coros evangélicos amadores. Rev CEFAC. 2006; 8(1):96-106.

21. Ribeiro RL, Hanayama EM. Perfil vocal de coralistas amadores. Rev CEFAC. 2005; 7(2):252-66. 22. Cruz TLB, Gama ACC, Hanayama EM. Análise da extensão e tessitura vocal do contratenor. Rev CEFAC. 2004; 6(4):423-8.

23. Zan JR. Música popular brasileira: indústria cultural e identidade. Eccos Rev Cient UNINOVE. 2005; 1(3):105-22.

24. Souza MG. História social da música popular brasileira. Rev História: Questões \& Debates. 2001; 4:299-303. 
25. Matos CN. Canção popular e performance vocal. [periódico online]. Disponível em: URL: http:// www.hist.puc.cl/historia/iaspmla.html

26. Napolitano M, Wasserman MC. Desde que o samba é samba: as questões das origens no debate historiográfico sobre a música popular brasileira. Rev Bras Hist. 2000; 20(39):167-89.

27. Oliveira $\mathrm{CM}$. A relação entre a música e fonoaudiologia, com ênfase no estilo gospel. J Bras Fonoaudiol. 2001;3(9):271-7.

28. Rosa PP. Levantamento da saúde vocal de uma amostra de cantores de pagode do município de Porto Alegre. Pró-Fono R Atual Cient. 2000; 12(2):87-91. 29. Hanayama EM, Tsuji DH, Pinho SRM. Voz metálica: estudos das características fisiológicas. Rev CEFAC. 2004; 6(4):436-45.

Recebido em: 10/08/2006

Aceito em: 05/10/2006

Endereço para correspondência:

Rua Aristides Lobo, 420

Maringá-PR

CEP: 87030-010

Tel/Fax: (44) 30286771

E-mail:cnishimura@bol.com.br 